\title{
Platelet factor 4 polyanion immune complexes: heparin induced thrombocytopenia and vaccine-induced immune thrombotic thrombocytopenia
}

\author{
Payel Datta, Fuming Zhang, Jonathan S. Dordick and Robert J. Linhardt ${ }^{*}$
}

\begin{abstract}
Background: This is a review article on heparin-induced thrombocytopenia, an adverse effect of heparin therapy, and vaccine-induced immune thrombotic thrombocytopenia, occurring in some patients administered certain coronavirus vaccines.

Main body/text: Immune-mediated thrombocytopenia occurs when specific antibodies bind to platelet factor 4 /heparin complexes. Platelet factor 4 is a naturally occurring chemokine, and under certain conditions, may complex with negatively charged molecules and polyanions, including heparin. The antibody-platelet factor 4/ heparin complex may lead to platelet activation, accompanied by other cascading reactions, resulting in cerebral sinus thrombosis, deep vein thrombosis, lower limb arterial thrombosis, myocardial infarction, pulmonary embolism, skin necrosis, and thrombotic stroke. If untreated, heparin-induced thrombocytopenia can be life threatening. In parallel, rare incidents of spontaneous vaccine-induced immune thrombotic thrombocytopenia can also occur in some patients administered certain coronavirus vaccines. The role of platelet factor 4 in vaccine-induced thrombosis with thrombocytopenia syndrome further reinforces the importance the platelet factor 4/polyanion immune complexes and the complications that this might pose to susceptible individuals. These findings demonstrate, how auxiliary factors can complicate heparin therapy and drug development. An increasing interest in biomanufacturing heparins from non-animal sources has driven a growing interest in understanding the biology of immune-mediated heparin-induced thrombocytopenia, and therefore, the development of safe and effective biosynthetic heparins.
\end{abstract}

Short conclusion: In conclusion, these findings further reinforce the importance of the binding of platelet factor 4 with known and unknown polyanions, and the complications that these might pose to susceptible patients. In parallel, these findings also demonstrate how auxiliary factors can complicate the heparin drug development.

Keywords: Biosynthetic heparins, HIT, VITT, COVID-19, PF4, Platelet factor 4/polyanion complex

\footnotetext{
*Correspondence: linhar@rpi.edu

Prepared for Thrombosis Journal, June 2021, revised August 2021b, September 2021.

Heparin Applied Research Center, Center for Biotechnology and

Interdisciplinary Studies, Rensselaer Polytechnic Institute, Troy, NY 12180, USA
}

(C) The Author(s). 2021 Open Access This article is licensed under a Creative Commons Attribution 4.0 International License, which permits use, sharing, adaptation, distribution and reproduction in any medium or format, as long as you give appropriate credit to the original author(s) and the source, provide a link to the Creative Commons licence, and indicate if changes were made. The images or other third party material in this article are included in the article's Creative Commons licence, unless indicated otherwise in a credit line to the material. If material is not included in the article's Creative Commons licence and your intended use is not permitted by statutory regulation or exceeds the permitted use, you will need to obtain permission directly from the copyright holder. To view a copy of this licence, visit http://creativecommons.org/licenses/by/4.0/. The Creative Commons Public Domain Dedication waiver (http://creativecommons.org/publicdomain/zero/1.0/) applies to the data made available in this article, unless otherwise stated in a credit line to the data. 


\section{Introduction}

Heparin is an essential life-saving drug and is extensively used as an anticoagulant [1]. Approximately 175 metric tons of heparin are used annually worldwide. Pharmaceutical heparin is animal-sourced and extracted from the porcine intestinal mucosa [2, 3]. Concerns over animal-sourced biopharmaceuticals, including contamination with prions, viruses, or processing impurities, has led to efforts to develop bioequivalent heparins from non-animal sources [4-22], which may be safer compared to animal-sourced products. Furthermore, bioequivalent heparins may diversify the existing supply chain [2].

Heparin-induced thrombocytopenia (HIT) is an adverse effect of heparin therapy. Type 1 HIT is a nonimmune disorder that results from the direct effect of heparin on platelet activation. Type 2 HIT is an immune-mediated disorder that typically occurs 4-10 days after exposure to heparin [23]. HIT occurs in a small fraction of patients (0.2 to 3\%) undergoing heparin therapy [24]. HIT is a complicated pathology and associated with life-threatening thromboembolic complications [23]. Prompt and accurate diagnosis is critical for HIT treatment. Therefore, understanding the biology of HIT is imperative towards HIT diagnosis and the development of bioequivalent heparins.

The current review includes an overview of: (1) heparin; (2) the biology of HIT; (3) current clinicopathological diagnosis of HIT; and (4) the regulatory importance on the development of bioequivalent heparins.

\section{Heparin}

Heparin is a negatively charged linear mucopolysaccharide and is naturally found in the granules of mast cells [25]. Heparin is composed of linear chains of disaccharide units of D-glucosamine and uronic acid (L-iduronic acid or D-glucuronic acid) [25]. These sugar moieties are sulfated (2.0-2.5 sulfate groups per disaccharide unit) The sulfation patterns on heparin dictate the interaction of heparin with various ligands [25], including proteins, which is domain-specific or charge-dependent [25-31]. Anticoagulant heparin has characteristic sulfated pentasaccharide domains that bind to antithrombin III (ATIII), which leads to inhibition of the blood coagulation cascade and results in anticoagulation [25, 32]. Heparin may interact with a myriad of ligands in a charge-dependent manner $[25,33,34]$. For example, the highly negatively charged heparin interacts with the positively charged proteins, such as platelet factor 4 (PF4, CXCL4) [33]. Importantly, the interaction of heparin and PF4 is associated with immune-mediated HIT [33].

Since 1977, heparin has been listed as essential medicine by the World Health Organization [35]. The therapeutic effects of heparin are based on the fact that heparin binds to specific proteins in the blood coagulation pathway and initiates a reaction cascade that leads to blood anticoagulation. As part of this cascade, heparin binds to ATIII, causes a conformational change in the protein, which increases the affinity of ATIII to bind to and inactivate coagulation enzymes, specifically, thrombin (Factor IIa) and Factor Xa. Heparin is used for the prophylaxis and treatment of medical conditions and surgical procedures that can lead to blood clotting, including acute myocardial infarction, arterial and venous thromboembolism, and lung thromboembolism. Different therapeutic heparins include unfractionated heparin (UFH, MW: $16 \mathrm{kDa}$ ), low-molecular weight heparin (LMWH, MW: $4.5 \mathrm{kDa}$ ), and ultra-low-molecular weight heparin, fondaparinux (ULMWH, MW: 1728) (Table 1). Current drug development efforts have focused on generating therapeutic heparins from non-animal sources and using chemoenzymatic methods.

\section{Heparin derivatives with reduced HIT}

Currently, heparins are manufactured by purification from animal tissues such as porcine intestines and bovine lungs [2, 3]. Due to the poor control of animal tissues, potentially limited availability, impurities, viruses, prions, and contamination, there has been increased interest in novel approaches for heparin production [36]. These novel approaches include chemical synthesis, chemoenzymatic synthesis, bioengineered/biosynthetic heparin, and recombinant heparin by metabolic engineering. The heparin derivative products, such as ULMWHs and LMWHs, can result in reduced HIT.

\section{Low molecular weight heparins (LMWHs)}

LMWHs are manufactured by the controlled chemical or enzymatic depolymerization of unfractionated heparin. The interaction between heparin and PF4 is sizedependent [37]. As a result, the absolute risk of HIT is $2-3 \%$ for unfractionated heparin, but LMWH can reduce the risk of HIT to $0.2-0.6 \%$ [38]. The incidence of HIT is influenced by the underlying disease or indication for heparin therapy. For example, HIT incidence is high in patients with cardiopulmonary bypass (CPB), sepsis, acute hemodialysis (HD), while the incidence is very low in the patients with potential venous thromboembolism (VTE) or chronic HD. Thus, the incidence of HIT for UFH and LMWH must take into account the underlying disease state of the patient. It is only in this context that there is a reasonable indication to prevent/treat VTE.

The differential immunogenicity and incidence of HIT with UFH and LMWH were first noted in a study by Warkentin et al. [39]. In this study of over 700 orthopedic patients randomized to receive prophylactic doses of UFH or LMWH, a lower incidence of HIT was 
Table 1 Comparison of UFH, LMWHs and fondaparinux

\begin{tabular}{|c|c|c|c|}
\hline $\begin{array}{l}\text { Anticoagulation } \\
\text { therapy }\end{array}$ & UFH & LMWH & Fondaparinux \\
\hline Nomenclature & Unfractionated heparin & $\begin{array}{l}\text { Two LMWHs based formulation (1) } \\
\left.\text { dalteparin (Fragmin }{ }^{\oplus}\right) \text { and (2) enoxaparin } \\
\left(\text { Lovenox }^{\oplus)}\right.\end{array}$ & Fondaparinux (Arixtra ${ }^{\oplus}$ ) \\
\hline $\begin{array}{l}\text { Mechanism of } \\
\text { action }\end{array}$ & $\begin{array}{l}\text { Bind to AT and increases the affinity of AT to } \\
\text { bind and inactivate both Fxa and thrombin }\end{array}$ & $\begin{array}{l}\text { Bind to AT and increases the affinity of AT } \\
\text { to bind and inactivate Fxa. } \\
\text { The effect on inactivation of thrombin is } \\
\text { relatively less. }\end{array}$ & $\begin{array}{l}\text { Bind to AT and increases the } \\
\text { affinity of AT to bind and } \\
\text { inactivate Fxa. }\end{array}$ \\
\hline Half life & $60-120 \mathrm{~min}$ & $\begin{array}{l}\text { (4-7 h) Enoxaparin } \\
2-5 \text { (dalteparin) }\end{array}$ & $17-21 \mathrm{~h}$ \\
\hline $\begin{array}{l}\text { Neutralization } \\
\text { with protamine } \\
\text { sulfate }\end{array}$ & Yes & Yes & $-N A-$ \\
\hline Clearance & $\begin{array}{l}\text { Hepatic \& Reticulo-endothelial system No } \\
\text { renal adjustments }\end{array}$ & Renal & Renal \\
\hline $\begin{array}{l}\text { Ability to cause } \\
\text { HIT }\end{array}$ & Yes & Yes & Low; Cases reported \\
\hline
\end{tabular}

observed (2.7\% UFH vs. $0 \%$ LMWH; $p=0.0018)$. Subsequent studies and a meta-analysis of approximately 7300 patients have confirmed nearly a 10-fold lower risk of HIT with use of a prophylactic dose LMWH as compared with UFH [38]. The differential effect, however, is not seen at therapeutic doses of UFH and LMWH [40]. In a meta-analysis of studies using these drugs at therapeutic doses, the incidence of clinical HIT appeared to be comparable (UFH 1.5\% vs. LMWH 1.2\%) [41].

There is one ULMWH, a chemically synthesized heparin pentasaccharide in clinical use, fondaparinux sodium (Arixtra). Fondaparinux has a linear pharmacokinetic profile, and a longer half-life and does not induce immune HIT compared to UFH and LMWH [42]. Fondaparinux is commonly used for the treatment of patients at risk of HIT despite a lack of approval for this indication [43].

\section{Chemoenzymatically synthesized ultra-low molecular weight heparins and heparin oligosaccharides}

Chemoenzymatic synthesis of heparin oligosaccharides includes two major steps; the first step is to generate the backbone using different nucleotide sugar substrates (uridine 5'-diphospho (UDP)- $N$-acetyl-D-glucosamine and UDP-D-glucuronic acid) and glycosyltransferases, while the second step is to modify the backbone using epimerase and different sulfotransferases $[8,44-46]$. There has been great progress in the chemoenzymatic synthesis of heparin derivatives, leading to gram scale production in the research laboratory $[9,13,18]$. A detailed characterization of the interaction of PF4 and HIT antibodies with homogeneous synthetic heparin oligosaccharides of 6-, 8-, 10-, and 12-mer and a hypersulfated 12-mer recently was reported [47]. Pure synthetic heparin oligosaccharides display stronger binding affinity to PF4 than animal-derived heparins of corresponding length. In contrast, HIT antibodies bind weakly to complexes formed between PF4 and heparins $\leq 8$-mer than with complexes formed between PF4 and heparins $\geq 10$ mer. The addition of one sulfate group to the heparin 12-mer resulted in substantial changes in its binding characteristics to PF4 [47].

\section{Recombinant heparin production by metabolic engineering of $\mathrm{CHO}$ cells}

Cellular production of heparin provides a single process alternative potentially under cGMP control. The Chinese Hamster Ovary $(\mathrm{CHO})$ cell line has been widely used as an industrial line for producing recombinant therapeutic products, and $\mathrm{CHO}$ cells produce substantial amounts of heparan sulfate (HS) [6]. In our previous study, $N$-deacetylase/ $\mathrm{N}$-sulfotransferase (NDST2) and mouse heparan sulfate 3-O-sulfotransferase 1 (Hs3st1) genes were successfully transfected sequentially into $\mathrm{CHO}$ cells [17, 48-51]. CHO-S cells, expressing Golgi-targeted Hs3st1 can produce recombinant heparin/HS with an increased anticoagulant activity $[17,48,49,51]$. We expect that through metabolic engineering, it is possible to direct cellular synthesis of heparin/HS to specific compositions with reduced risk of HIT without changing the potency of anticoagulation. For example, it was reported that removal of 2-O-sulfate from HS results in significant increases in the $\mathrm{IC}_{50}$ for PF4 binding to heparin in competition formats [52], unfortunately, 2-O-sulfate is a required component of the ATIII binding site, critical for anticoagulant activity.

\section{Biosynthetic heparin}

We have produced biosynthetic heparin by E. coli K5 fermentation (to prepare heparosan) and 
chemoenzymatic methods [44]. The heparosan was first chemically converted to $\mathrm{N}$-sulfo-heparosan and then modified by a three-step enzymatic process to obtain anticoagulant biosynthetic heparin [10, 20]. Using this approach, multigram quantities of chemically and biologically equivalent biosynthetic heparin to that of USP heparin have been demonstrated. Preliminary studies show that biosynthetic heparin showed a similar interaction profile to PF4 as USP heparin [37]. By fine-tuning enzymatic modification, it may be possible to generate biosynthetic heparin with altered structures giving good anticoagulation activity but reduced risk of HIT.

\section{Regulatory importance of the development of bioequivalent heparins}

Every country has their regulatory bodies that oversee the drug approval process, for example, the European Medicines Agency in European Union and the Food and Drug Administration in the United States [53]. Specifically, the U.S. FDA regulates pharmaceutical and biopharmaceutical drug development and commercialization via the Center for Drug Evaluation and Research (CDER) and the Center for Biologics Evaluation and Research (CBER), respectively. In 198788 , the regulations of biological products were split between CDER and CBER. CDER regulates prescription drugs, over-the-counter drugs (OTCs), generic drugs, and specific biological products, including, recombinant proteins, monoclonal antibodies (mABs), hormones, thrombolytics and immunomodulators. CBER regulates specific biological products, including, allergenics, blood derivatives, blood and blood products, cellular therapies, and vaccines. As part of the review process, the FDA directs the regulatory pathway for innovator pharmaceuticals, generics, biologics, and biosimilars. Although the regulatory pathways may have certain differences, all the regulatory pathways focus on drug safety and efficacy.

Addressing the HIT and immunogenic potential of biosynthetic heparins during the drug development and approval processes is critical. With the growing interest in developing new non-animal sourced heparins, it is vital to develop robust and sensitive analytical tools to address the HIT potential of biosynthetic heparins. Currently, most available HIT analysis is focused on the clinical management of HIT (e.g., clinicopathological diagnosis of HIT). In vitro assessment, rather than clinical evaluation provides the best prediction of the potential for developing HIT. Development of robust and sensitive analytical and diagnosis tools is critical to evaluate the interaction of heparin and PF4, as well immunogenic potential of the heparin/PF4 complexes. Examples of in vitro and analytical tools towards evaluating the biomolecular interaction of heparin and PF4 may include, but are not limited to: (1) binding kinetics studies (e.g., surface plasmon resonance, SPR); (2) heparin-PF4 ULIC complex size (e.g., electron microscopy); and (3) heparin-PF4 complex charge and stoichiometric ratio (e.g., zeta potential). The applications may include comparative studies of heparins from various sources, evaluating lot variability, and process development of bioequivalent heparins, among others.

\section{Biology of HIT}

HIT (Type II) is immune-mediated drug-associated thrombocytopenia [54]. Type II HIT occurs when specific antibodies bind to the heparin-PF4 complex and lead to platelet activation. Platelet activation, accompanied by other cascading reactions, leads to cerebral sinus thrombosis, DVT, lower limb arterial thrombosis, myocardial infarction, pulmonary embolism, skin necrosis, and thrombotic stroke. If untreated, HIT may be life threatening. The current section focuses on (1) PF4 structure, (2) Biological and clinical importance of PF4, (3) heparin and PF4 interaction, (4) current knowledge of HIT antibodies, and (5) pathophysiology of HIT.

\section{Platelet factor 4 (PF4, CXCL4)}

Platelet factor 4 (PF4, CXCL4) is a naturally occurring positively charged chemokine. The mature monomeric PF4 protein sequence consists of 70 amino acids (7.8 $\mathrm{kDa}$ ). At equilibrium, PF4 may exist as a monomer, homodimer, homotrimer or homotetramer. The homotetrameric form of PF4 forms a cylindrical structure and comprises an equatorial ring (Fig. 1). The equatorial ring is composed of positively charged amino acids and forms the binding site for negatively charged polyanions, including heparin. A minimum amount of PF4 must be present in circulating blood in order for anti-heparin PF4 antibody to be formed. Indeed, the presence of PF4 in blood is the most proximal event in the pathogenesis of HIT. However, in recent years, there has been little interest in measuring/studying PF4 prior to the formation of anti-heparin PF4 antibody.

\section{Biological and clinical importance of platelet factor 4 (PF4, CXCL4)}

PF4 may play a role in innate immune responses through binding to polyanionic lipids of bacterial cellular walls (Gram-positive and Gram-negative) [55, 56]. Recently, PF4 also has been associated with vector-based SARS-CoV-2 vaccine-induced thrombosis with thrombocytopenia syndrome (VITT/TTS), thus, emphasizing the clinical significance of PF4 in PF4/polyanion complex formation, and the occurrence of VITT/TTS [57-62]. Administration of ChAdOx1 nCov-19 vaccines results in rare incidents of spontaneous VITT in some patients [63]. Vaccines contaminated with significant amounts of host cell protein (HCP) impurities may be 


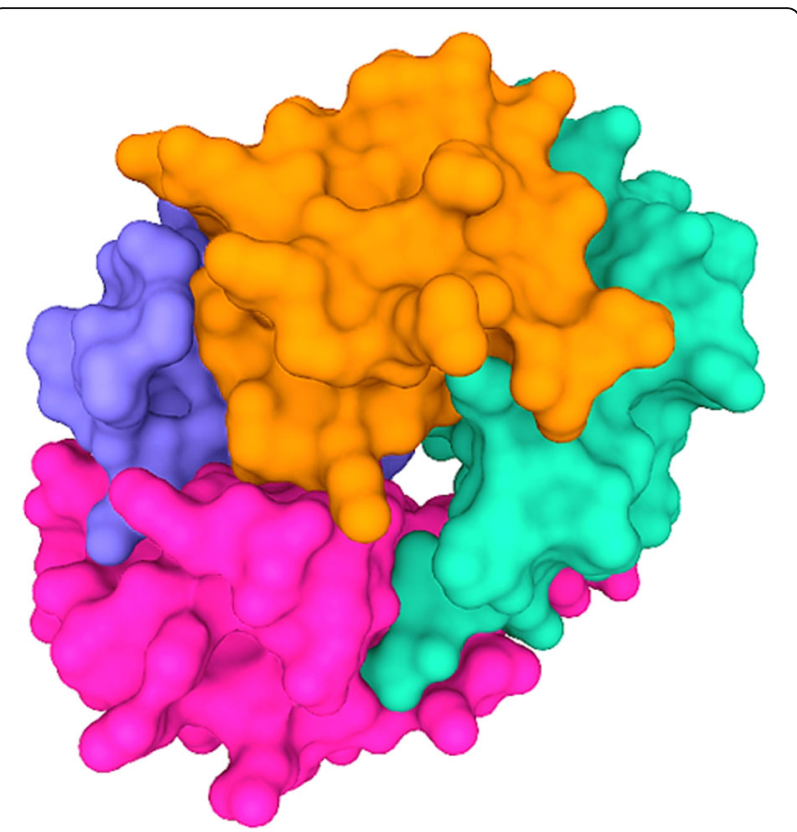

Fig. 1 The homotetrameric form of PF4 forms a cylindrical structure and comprises of an equatorial ring. Four PF4 monomers (https:// www.uniprot.org/uniprot/P02776, accessed on May 2021) form a homotetrameric complex. The homotetrameric complex bind to highly negative molecules and polyanions, including heparin. PF4 structure and images created using Mol* (D. Sehnal, S. Bittrich, M. Deshpande, R. Svobodová, K. Berka, V. Bazgier, S. Velankar, S.K. Burley, J. Koča, A.S. Rose (2021) Mol* Viewer: modern web app for 3D visualization and analysis of large biomolecular structures. Nucleic Acids Research. doi: https://doi.org/10.1093/nar/gkab314). The structure and information of PF4 (1F1F9Q) was obtained from RCSB PDB (https://www.rcsb.org/structure/1f9q, accessed in May 2021)

one of the causative factors for VITT [64]. Researchers have demonstrated that ChAdOx1 nCoV-19 (AstraZeneca) contained significant amounts of HCPs, including functionally active proteasomes and adenovirus protein impurities [64]. PF4 can complex with the ChAdOx1 nCoV-19 constituents of this vaccine. Researchers also evaluated the Ad26.COV2.S vaccine (Johnson \& Johnson). The Ad26.COV2.S vaccine contained a much lower amount of impurities. Importantly, PF4 did not appear to complex with the purified forms of ChAdOx1 nCoV-19 or with Ad26.COV2.S virions. Researchers showed that ChAdOx1 nCoV-19, but not Ad26.COV2.S, induced vascular hyperpermeability [64].

The role of PF4 in VITT/TTS further reinforces the importance the binding of PF4 with known and unknown polyanions, and the complications that these might pose to patients susceptible to HIT. These findings show the importance of evaluating biosynthetic heparins and their HIT potential. In parallel, these findings also demonstrate how auxiliary factors can complicate the heparin drug development pathway.

\section{Heparin and PF4 interaction: formation of immunogenic} ultra-large complexes

The formation of the heparin-PF4 complex is a chargedependent and stoichiometrically driven phenomenon $[23,52,65]$. Sensitive analytical tools have aided the understanding of biomolecular interaction of heparin and PF4 in vitro, including: (1) PF4-heparin kinetics (e.g., via surface plasmon resonance); (2) PF4-heparin complex size (e.g., via electron microscopy); and (3) heparin-PF4 complex formation (e.g., via zeta potential) [37]. Ultralarge heparin-PF4 immune complexes (ULICs, > 670 $\mathrm{kDa})$ are associated with HIT pathogenesis [23]. The ULICs form at an equimolar ratio of heparin and PF4 in vitro [37] (Fig. 2). The formation of ULICs also depends on the heparin chain size, and heparin chains with at least 12 saccharides are necessary to form ULICs [23]. The incidence of HIT is highest with UFH, fewer with LMWH, and none with fondaparinux [66]. Fondaparinux can bind to PF4 but these complexes are weakly recognized by HIT antibodies. However, it has been reported in certain cases (e.g., aortic stent-graft placement and stroke), patients may develop fondaparinux associated HIT [66-74]. HIT is a complex phenomenon, and with the advances in molecular biology and bioanalytical tools, the role of other factors (e.g., disease status, and/ or genetics) in the incidence of HIT may be uncovered.

Patients who have been previously exposed to heparin, and, thus, have been sensitized to the heparin-PF4 immune complex, produce anti-PF4-heparin antibodies [23]. The key anti-PF4-heparin antibodies are immunoglobulin G, (IgG, 80\%), and may also include other immunoglobulins, including IgA and IgM [75-78]. Specific antibodies bind to the PF4/heparin complex $[79,80]$. In animal models, specific HIT antibodies (e.g., murine monoclonal HIT-like monoclonal antibody) binds to the PF4/heparin complex and elicits HIT [80]. The crystal structure of PF4 interacting with fondaparinux and the HIT-like monoclonal antibody reveals that the PF4 tetramers cluster around heparin, and multiple HIT-like monoclonal antibodies bind to the outer surface of PF4 tetramers [23, 80, 81]. With the development of sophisticated analytical tools, researchers have solved the crystal structures of the: (1) homotetrameric PF4 tetramer complexed with fondaparinux; (2) homotetrameric PF4 complexed with the KKO-Fab (a murine HIT-like monoclonal antibody); and (3) monomeric PF4 complexed with the RTO-Fab (a nonHIT anti-PF4 monoclonal antibody) [82]. KKO (Anti-human PF4 monoclonal antibodies to PF4; KKO causes thrombocytopenia in an in vivo model of HIT) and RTO (Anti-human PF4 monoclonal antibodies to PF4, RTO does not cause thrombocytopenia in an in vivo model of HIT) have been characterized, including their amino acid sequences [83]. This results in the formation of ultra-large HIT immune complexes (ULICs) [23, 80, 81]. 


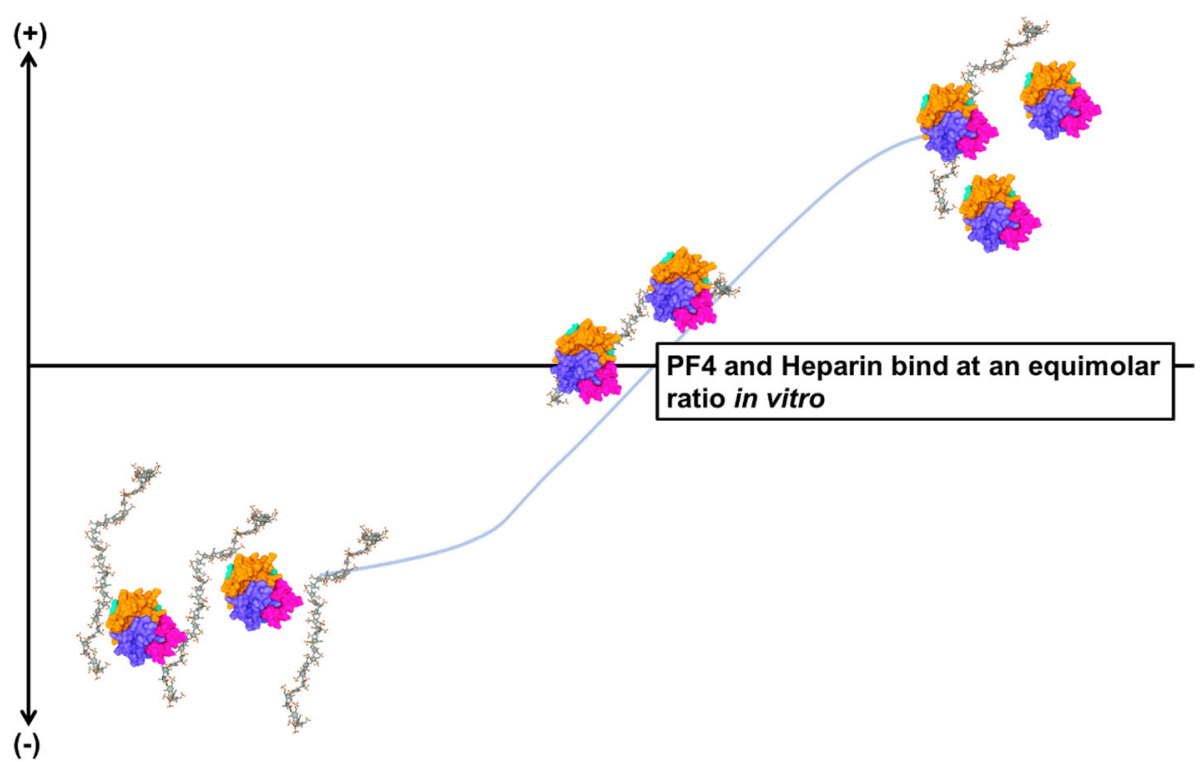

Fig. 2 Binding of PF4 and heparin is a stoichiometrically driven phenomenon. Both PF4 and heparin structure and images created using Mol* (D. Sehnal, S. Bittrich, M. Deshpande, R. Svobodová, K. Berka, V. Bazgier, S. Velankar, S.K. Burley, J. Koča, A.S. Rose (2021) Mol* Viewer: modern web app for 3D visualization and analysis of large biomolecular structures. Nucleic Acids Research. doi: https://doi.org/10.1093/nar/gkab314). The structure and information of PF4 (1F1F9Q) was obtained from RCSB PDB (https://www.rcsb.org/structure/1f9q, accessed in May 2021). The structure and information of representative heparin was obtained from RCSB PDB (https://www.rcsb.org/structure/3irl, accessed in May 2021)

ULICs mediate the immune response and subsequently HIT pathogenesis [23]. Certain antibodies (e.g., murine RTO) bind to the PF4/heparin complex but do not form ULICs [23, 80]. Non-pathogenic antibodies bind to PF4 and prevent tetrameric PF4 formation [23, 80]. Tetrameric PF4 is critical for ULIC formation [23]. The researchers further have shown that certain (nonpathogenic) antibodies are HIT blocking antibodies, and inhibit the in vitro and in vivo platelet-activating ability of $\mathrm{KKO}[23,80]$.

\section{Pathophysiology of HIT}

ULIC recognizes and binds to specific cell surface receptors on, platelets, monocytes, neutrophils, and endothelial cells [84]. For example, binding of the HIT immune complex to FcyRIIa (CD32) platelets induces platelet activation, aggregation, and degranulation [85]. Platelet activation leads to the release of procoagulants, microparticles and serotonin. The release of procoagulants leads to cascading events, including thrombin generation and thrombosis. The release of serotonin is a direct measure of heparin-dependent platelet activation [84]. The presence of HIT antibodies in a patients' serum can be assessed using a serotonin release assay [84]. Platelet aggregation leads to a decrease in platelet count $\left(<1.5 \times 10^{11} / \mathrm{L}\right.$ or $<50 \%$ of baseline platelet count) [84]. The decrease in platelet count, with the addition of other associated symptoms, may indicate HIT and can be used in HIT clinicopathological diagnosis (discussed below). The binding of ULICs to monocytes leads to tissue factor (TF) expression on the monocytes and peripheral blood mononuclear cells (PBMCs) [23, 85-87]. An increase in TF leads to activation of the blood coagulation cascade and the generation of coagulation proteases, such as Factor Xa (FXa) and thrombin [23, 85-87]. HIT antibodies can also interact with other glycosaminoglycans, including HS present on endothelial cells [23, 85-87]. This interaction can cause activation of TFs and a cascading reaction resulting in endothelial damage. The activation of TFs also may lead to increased production of thrombin and platelet activation [23], the latter also leading to the release of additional PF4 and subsequently aggravating the symptoms of HIT [23].

\section{Clinicopathological diagnosis of HIT}

The clinicopathological diagnosis of HIT includes $4 \mathrm{~T}$ scoring system and laboratory testing [84, 88-90]. Various laboratory tests are commonly used to evaluate HIT diagnosis, and fall under two broad categories, immunoassays that evaluate the presence of HIT antibodies (e.g., anti-PF4-heparin enzyme-linked immunoassays) and functional assays that evaluate the ability of the HIT antibodies to activate platelets (e.g., serotonin release assays, SRA). The combinatorial knowledge from $4 \mathrm{~T}$ score analysis and laboratory tests may prevent misdiagnosis. Moreover, understanding the principles, advantages, and drawbacks of the $4 \mathrm{~T}$ scoring system and laboratory tests 
may aid in further development of bioequivalent heparins with low propensity of causing HIT.

\section{$4 \mathrm{~T}$ scoring system}

The $4 \mathrm{~T}$ scoring system is a validated, clinical risk analysis tool and utilizes clinical findings to estimate the probability of HIT [91-95]. Four factors define the $4 \mathrm{~T}$ score analysis: (1) the timing of onset of platelet count decrease; (2) thrombocytopenia; (3) thrombosis or other sequelae; and (4) other causes of thrombocytopenia (Table 2). A high $4 \mathrm{~T}$ score ( $>5$ points) and intermediate $4 \mathrm{~T}$ score (4-5) is indicative of a high probability of HIT and requires further laboratory testing [96]. A low $4 \mathrm{~T}$ score (0-3) may not be indicative of likelihood of HIT [96]. The 4Ts score has a negative predictive value (NPV) of approximately $100 \%$. The limitations of the $4 \mathrm{~T}$ scoring system, such a significant inter-observer variability and modest positive predictive value (PPV), have led to exploration of alternate scoring systems [97].

\section{Lab testing: immunoassays}

Immunoassays can be used to evaluate the binding of HIT antibodies to PF4/heparin (or PF4/polyanion) complexes [91, 95, 98], which may result in immune thrombosis and thrombocytopenia. Rare incidents of spontaneous vaccine-induced immune thrombotic thrombocytopenia have occurred in some patients who were administered with the ChAdOx1 $\mathrm{nCov}-19$ vaccines $[63,99]$. The most widely used immunoassays for assessing HIT are PF4-dependant enzyme immunoassays (EIAs) [91, 100, 101]. The principal of the assay is based on enzyme-linked immunosorbent assay (ELISA) [91, 100, 101]. The EIAs are rapid and commercially available, and often exhibit high sensitivity (95-97\%) and high negative predictive value [98]. However, EIAs may lack high specificity and positive predictive value [98]. The lack of specificity arises from the fact that EIAs detect total HIT antibodies. Other available immunoassays include the particle immunofiltration assay (PIFA) and functionalized immunoassay (e.g., latex immunoturbidimetric assay, LIA).

\section{Lab testing: functional assays}

Functional assays are used to test whether patientderived HIT antibodies can induce platelet activation (from healthy donors) in a heparin-dependent manner [89, 92, 95, 101-103]. The tests are performed using whole blood (WB), platelet-rich plasma (PRP), or isolated washed platelets (WP) from healthy donors [89, 92, 95, 101-103]. Serotonin release assay (SRA) is the gold standard for HIT diagnosis [89, 103]. The SRA evaluates the ability of patients HIT antibodies to activate donor platelets. HIT antibodies will activate platelets and release serotonin, which directly correlates to a positive HIT diagnosis $[89,103]$. This assay is sensitive to HIT antibodies and is highly specific (>90\%) [89, 103]. However, the SRA is expensive and time-consuming [89, 103].

Other functional assays include those based on platelet aggregation and measurement of specific biomarkers on activated platelets $[89,92,95,101-103]$. Functional assays based on the principles of platelet aggregation include heparin-induced platelet aggregation (HIPA), light transmission aggregometry (LTA), and heparin-induced multiple electrode aggregometry (HIMEA) [89, 92, 95, 101-104]. Functional assays based on flow cytometry, include analysis of increased expression of CD62P (P selectin) or phosphatidylserine expressions on activated platelets [89, 92, 95, 101-103].

Table 2 4T Scoring system: A pretest score for evaluating probability of HIT

\begin{tabular}{|c|c|c|c|}
\hline Factors & 2-points & 1-point & 0-point \\
\hline $\begin{array}{l}\text { The timing of onset of } \\
\text { platelet count decrease }\end{array}$ & $\begin{array}{l}\text { - Clear onset of platelet count decrease } \\
\text { (5-10 days) } \\
\text { - Platelet count decrease } \leq 1 \text { day, if last } \\
\text { heparin exposure is within } 30 \text { days }\end{array}$ & $\begin{array}{l}\text { - Suspected 5-10 days but was not documented or } \\
\text { missing } \\
\text { - Onset of platelet decrease after } 10 \text { days or } \leq 1 \text { day, } \\
\text { with the last heparin exposure at } 30-100 \text { days ago }\end{array}$ & $\begin{array}{l}\cdot<4 \text { days with no } \\
\text { recent heparin } \\
\text { exposure }\end{array}$ \\
\hline Thrombocytopenia & $\begin{array}{l}\text { - Platelet count fall is }>50 \% \text { and } \\
\text { - Platelet nadir } \geq 20 \times 10^{9} / \mathrm{L}\end{array}$ & $\begin{array}{l}\text { - Platelet count fall is } 30-50 \% \text { or/and } \\
\text { - Platelet nadir }=10-19 \times 10^{9} / \mathrm{L}\end{array}$ & $\begin{array}{l}\cdot \text { Platelet count fall is } \\
<30 \% \\
\text { Or/and } \\
\text { - Platelet nadir }<10 \times \\
10^{9} / L\end{array}$ \\
\hline $\begin{array}{l}\text { Thrombosis or other } \\
\text { sequelae, }\end{array}$ & $\begin{array}{l}\text { - New thrombosisor/and } \\
\text { - Skin lesions or necrosis at the heparin } \\
\text { injection sitesor/and } \\
\text { - Acute systemic reaction (post- } \\
\text { intravenous heparin injection) }\end{array}$ & $\begin{array}{l}\text { - Progressive thrombosisand/or } \\
\text { - Recurrent thrombosis } \\
\text { Or/and } \\
\text { - Non-necrotic (erythematous) skin lesions } \\
\text { Or/and } \\
\text { - Silent, suspected }\end{array}$ & - None \\
\hline $\begin{array}{l}\text { Other causes of } \\
\text { thrombocytopenia }\end{array}$ & None & Possible & Defined \\
\hline
\end{tabular}




\section{Conclusions}

Heparin is an essential life-saving drug and is extensively used as an anticoagulant. However, HIT Type II is an adverse immune-mediated effect of heparin therapy. HIT occurs when specific antibodies bind to PF4/heparin complexes and result in cascading immune response, leading to thrombosis and thrombocytopenia. HIT is life threatening, although it occurs only in a small fraction of patients undergoing heparin therapy, suggesting a role of other contributing factors, which may include disease status and genetics. Current developments in COVID and vaccine research have also highlighted the clinical significance of PF4 in PF4/polyanion complex formation and incidence of vaccine-mediated thrombocytopenia.

Emerging efforts towards biosynthetic heparins from non-animal sources, have led to an increasing interest in understanding the biology of HIT, and developing safe and effective biosynthetic heparins. Knowledge of the biology of immune-induced thrombosis and thrombocytopenia may aid in predicting HIT potential of bioequivalent heparins.

\section{Acknowledgements}

Not applicable.

\section{Authors' contributions}

PD contributed to the literature search and PD and RJL wrote the first draft of the manuscript. FZ, JSD and RJL revised, and edited the manuscript. All authors approved the final manuscript as well as submission.

\section{Funding}

No financial support is received for this work

\section{Availability of data and materials}

Not applicable.

\section{Declarations}

Ethics approval and consent to participate

Not applicable.

\section{Consent for publication}

Not applicable.

\section{Competing interests}

No conflict of interests is reported for this work.

Received: 21 June 2021 Accepted: 1 September 2021

Published online: 15 September 2021

\section{References}

1. Linhardt RJ. 2003 Claude S. Hudson award address in carbohydrate chemistry. Heparin: structure and activity. J Med Chem. 2003;46(13):2551-64. https://doi.org/10.1021/jm030176m.

2. Fareed J, Jeske W, Ramacciotti E. Porcine mucosal heparin shortage crisis! What are the options? Clin Appl Thromb. 2019;25:1-3 https://doi.org/10.11 77/1076029619878786

3. Zhang F, Yang B, Ly M, Solakyildirim K, Xiao Z, Wang Z, et al. Structural characterization of heparins from different commercial sources. Anal Bioanal Chem. 2011:401(9):2793-803. https://link.springer.com/article/10.1007/s0021 6-011-5367-7.
4. Badri A, Williams A, Linhardt RJ, Koffas MA. The road to animal-free glycosaminoglycan production: current efforts and bottlenecks. Curr Opin Biotechnol. 2018;53:85-92 https://doi.org/10.1016/j.copbio.2017.12.018.

5. Thacker BE, Sharfstein ST. Metabolic engineering of mammalian cells to produce heparan sulfates. Emerg Top Life Sci. 2018;2(3):443-52. https://doi. org/10.1042/ETLS20180007.

6. Liu J, Linhardt RJ. Chemoenzymatic synthesis of heparan sulfate and heparin. Nat Prod Rep. 2014;31(12):1676-85. https://doi.org/10.1039/c4 np00076e.

7. Xiong J, Bhaskar U, Li G, Fu L, Li L, Zhang F, et al. Immobilized enzymes to convert $\mathrm{N}$-sulfo, $\mathrm{N}$-acetyl heparosan to a critical intermediate in the production of bioengineered heparin. J Biotechnol. 2013;167(3):241-7. https://doi.org/10.1016/j.jbiotec.2013.06.018.

8. Lee $\mathrm{S}$, Raw A, Yu L, Lionberger R, Ya N, Verthelyi D, et al. Scientific considerations in the review and approval of generic enoxaparin in the United States. Nat Biotechnol. 2013;3(3):220-6. https://doi.org/10.1038/nbt.2 528.

9. Baik JY, Gasimli L, Yang B, Datta P, Zhang F, Glass CA, et al. Metabolic engineering of Chinese hamster ovary cells: towards a bioengineered heparin. Metab Eng. 2012;14(2):81-90. https://doi.org/10.1016/j.ymben.2012. 01.008 .

10. Xu Y, Masuko S, Takieddin M, Xu H, Liu R, Jing J, et al. Chemoenzymatic synthesis of homogeneous ultralow molecular weight heparins. Science (80). 2011:498-501. https://doi.org/10.1126/science.1207478.

11. Wang Z, Yang B, Zhang Z, Ly M, Takieddin M, Mousa S, et al. Control of the heparosan $\mathrm{N}$-deacetylation leads to an improved bioengineered heparin. Appl Microbiol Biotechnol. 2011;91(1):91-9. https://doi.org/10.1007/s00253011-3231-5.

12. Zhang Z, McCallum SA, Xie J, Nieto L, Corzana F, Jiménez-Barbero J, et al. Solution structures of chemoenzymatically synthesized heparin and its precursors. J Am Chem Soc. 2008;130(39):12998-3007. https://pubmed.ncbi. nlm.nih.gov/18767845/. https://doi.org/10.1021/ja8026345.

13. Linhardt RJ, Dordick JS, Deangelis PL, Liu J. Enzymatic synthesis of glycosaminoglycan heparin. Semin Thromb Hemost. 2007:453-65 http:// www.thieme-connect.de/DOI/DOI?10.1055/s-2007-982076.

14. Lindahl U, Li JP, Kusche-Gullberg M, Salmivirta M, Alaranta S, Veromaa T, et al. Generation of "neoheparin" from E. coli K5 capsular polysaccharide. J Med Chem. 2005:48(2):349-52. https://doi.org/10.1021/jm049812m.

15. Glass CA. Recombinant heparin-New opportunities. Front Med. 2018;5:341 https://pubmed.ncbi.nlm.nih.gov/30564580/.

16. Sommers CD, Ye H, Liu J, Linhardt RJ, Keire DA. Heparin and homogeneous model heparin oligosaccharides form distinct complexes with protamine: light scattering and zeta potential analysis. J Pharm Biomed Anal. 2017;140: 113-21. https://doi.org/10.1016/j.jpba.2017.03.010.

17. Fu L, Li K, Mori D, Hirakane M, Lin L, Grover N, et al. Enzymatic generation of highly anticoagulant bovine intestinal heparin. J Med Chem. 2017;60(20): 8673-9. https://doi.org/10.1021/acs.jmedchem.7b01269.

18. Xu Y, Chandarajoti K, Zhang X, Pagadala V, Dou W, Hoppensteadt DM, et al. Synthetic oligosaccharides can replace animal-sourced low-molecular weight heparins. Sci Transl Med. 2017;9(406):5954. https://pubmed.ncbi.nlm. nih.gov/28878012/. https://doi.org/10.1126/scitranslmed.aan5954.

19. b Fu L, Suflita M, Linhardt RJ. Bioengineered heparins and heparan sulfates. Adv Drug Deliv Rev. 2016:97:237-49. https://doi.org/10.1016/j.addr.2015.11.002.

20. Bhaskar U, Li G, Fu L, Onishi A, Suflita M, Dordick JS, et al. Combinatorial one-pot chemoenzymatic synthesis of heparin. Carbohydr Polym. 2015;122: 399-407. https://doi.org/10.1016/j.carbpol.2014.10.054.

21. Fu L, Zhang F, Li G, Onishi A, Bhaskar U, Sun P, et al. Structure and activity of a new low-molecular-weight heparin produced by enzymatic ultrafiltration. J Pharm Sci. 2014;103(5):1375-83. https://doi.org/10.1002/ jps.23939.

22. Xu Y, Cai C, Chandarajoti K, Hsieh PH, Li L, Pham TQ, et al. Homogeneous low-molecular-weight heparins with reversible anticoagulant activity. Nat Chem Biol. 2014;10(4):248-50. https://www.nature.com/articles/nchembio.14 59. https://doi.org/10.1038/nchembio.1459.

23. Arepally GM, Cines DB. Pathogenesis of heparin-induced thrombocytopenia Transl Res. 2020;225:131-40. https://pubmed.ncbi.nlm.nih.gov/32417430/. https://doi.org/10.1016/j.trsl.2020.04.014

24. Arnold DM, Nazi I, Warkentin TE, Smith JW, Toltl LJ, George JN, et al. Approach to the diagnosis and management of drug-induced immune thrombocytopenia. Transfus Med Rev. 2013:27(3):137-45. https://pubmed. ncbi.nlm.nih.gov/23845922/. https://doi.org/10.1016/j.tmrv.2013.05.005. 
25. Zhang F, Zhang Z, Linhardt, RJ. Glycosaminoglycans. In Handb Glycomics. 2010;59-80. https://www.sciencedirect.com/science/article/pii/B978012373 6000000032.

26. Kim SY, Jin W, Sood A, Montgomery DW, Grant OC, Fuster MM, et al. Characterization of heparin and severe acute respiratory syndrome-related coronavirus 2 (SARS-CoV-2) spike glycoprotein binding interactions. Antivir Res. 2020;181:104873 https://doi.org/10.1016/j.antiviral.2020.104873.

27. Magro G. COVID-19: review on latest available drugs and therapies against SARS-CoV-2. Coagulation and inflammation cross-talking. Virus Res. 2020; 286:198070. https://doi.org/10.1016/j.virusres.2020.198070.

28. Kwon PS, Oh H, Kwon SJ, Jin W, Zhang F, Fraser K, et al. Sulfated polysaccharides effectively inhibit SARS-CoV-2 in vitro. Cell Discov. 2020:50 https://doi.org/10.1038/s41421-020-00192-8.

29. Soares da Costa D, Reis RL, Pashkuleva I. Sulfation of glycosaminoglycans and its implications in human health and disorders. Annu Rev Biomed Eng. 2017;19:1-26 http://www.annualreviews.org/doi/10.1146/annurev-bioeng071516-044610.

30. Xiong A, Kundu S, Forsberg-Nilsson K. Heparan sulfate in the regulation of neural differentiation and glioma development. FEBS J. 2014;281(22):49935008. http://doi.wiley.com/10.1111/febs.13097.

31. Capila I, Linhardt RJ. Heparin - protein interactions. Angew Chem. 2002; 41(3):391-412. https://doi.org/10.1002/1521-3773(20020201)41:3\%3C390::A ID-ANIE390\%3E3.0.CO;2-B.

32. Onishi A, St Ange K, Dordick JS, Linhardt RJ. Heparin and anticoagulation. Front Biosci - Landmark. 2016;21(7):1372-92. https://doi.org/10.2741/4462.

33. Arepally GM. Heparin-induced thrombocytopenia. Blood. 2017:2864-72. https://doi.org/10.1182/blood-2016-11-709873.

34. Chudasama SL, Espinasse B, Hwang F, Qi R, Joglekar M, Afonina G, et al. Heparin modifies the immunogenicity of positively charged proteins. Blood. 2010;116(26):6046-53. https://doi.org/10.1182/blood-2010-06-292938.

35. Ong CS, Marcum JA, Zehr KJ, Cameron DE. A century of heparin. Ann Thorac Surg. 2019;108(3):955-8. https://pubmed.ncbi.nlm.nih.gov/31077659/. https://doi.org/10.1016/j.athoracsur.2019.03.104.

36. Jin W, Zhang F, Linhardt RJ. Bioengineered production of glycosaminoglycans and their analogues. Syst Microbiol Biomanufacturing 2020;1(2):123-30. https://doi.org/10.1007/s43393-020-00011-x.

37. Zhang F, Datta P, Dordick JS, Linhardt RJ. Evaluating heparin products for heparin-induced thrombocytopenia using surface plasmon resonance. J Pharm Sci. 2020;109(2):975-80. https://doi.org/10.1016/j.xphs.2019.10.040.

38. Martel N, Lee J, Wells PS. Risk for heparin-induced thrombocytopenia with unfractionated and low-molecular-weight heparin thromboprophylaxis: a meta-analysis. Blood. 2005;106(8):2710-5. https://doi.org/10.1182/blood-2 005-04-1546.

39. Warkentin TE, Levine MN, Hirsh J, Horsewood P, Roberts RS, Gent M, et al. Heparin-induced thrombocytopenia in patients treated with low-molecularweight heparin or unfractionated heparin. N Engl J Med. 1995;332(20):1330 6. https://doi.org/10.1056/NEJM199505183322003.

40. Morris TA, Castrejon S, Devendra G, Gamst AC. No difference in risk for thrombocytopenia during treatment of pulmonary embolism and deep venous thrombosis with either low-molecular-weight heparin or unfractionated heparin: a metaanalysis. Chest. 2007;132(4):1131-9. https:// doi.org/10.1378/chest.06-2518.

41. Stein PD, Hull RD, Matta F, Yaekoub AY, Liang J. Incidence of thrombocytopenia in hospitalized patients with venous thromboembolism. Am J Med. 2009;122(10):919-30. https://doi.org/10.1016/j.amjmed.2009.03.026.

42. Mohamed S, Coombe DR. Heparin mimetics: Their therapeutic potential. Pharmaceuticals. 2017;10(4):78 https://pubmed.ncbi.nlm.nih.gov/28974047/.

43. Linkins $L A, H u$ G, Warkentin TE. Systematic review of fondaparinux for heparin-induced thrombocytopenia: when there are no randomized controlled trials. Res Pract Thromb Haemost. 2018;2(4):678-83. http://doi. wiley.com/10.1002/rth2.12145.

44. Biosynthetic heparin. https://patents.google.com/patent/US20190225998A1/ en. Accessed 9 Sept 2021.

45. Datta P, Linhardt RJ, Sharfstein ST. An 'omics approach towards $\mathrm{CHO}$ cell engineering. Biotechnol Bioeng. 2013;110(5):1255-71. http://doi.wiley.com/1 0.1002/bit.24841.

46. Datta P, Linhardt RJ, Sharfstein ST. Industrial production of glycosaminoglycans. Encycl Microbiol. 2019:681-90. https://doi.org/10.1016/ B978-0-12-809633-8.12224-1.

47. Nguyen T, Xu Y, Brandt S, Mandelkow M, Raschke R, Strobel U, et al. Characterization of the interaction between platelet factor 4 and homogeneous synthetic low molecular weight heparins. J Thromb Haemost. 2020;18(2):390-8. https://onlinelibrary.wiley.com/doi/abs/10.1111/ jth.14657.

48. Datta P, Yang B, Linhardt RJ, Sharfstein ST. Modulation of heparan sulfate biosynthesis by sodium butyrate in recombinant $\mathrm{CHO}$ cells. Cytotechnology. 2015;67(2):223-35. https://doi.org/10.1007/s10616-013-9677-9.

49. Baik JY, Dahodwala H, Oduah E, Talman L, Gemmill TR, Gasimli L, et al. Optimization of bioprocess conditions improves production of a $\mathrm{CHO}$ cellderived, bioengineered heparin. Biotechnol J. 2015;10(7):1067-81. http://doi. wiley.com/10.1002/biot.201400665.

50. Zhao X, Yang B, Linkens K, Datta P, Onishi A, Zhang F, et al. Microscale separation of heparosan, heparan sulfate, and heparin. Anal Biochem. 2013; 434(2):215-7. https://doi.org/10.1016/j.ab.2012.12.009.

51. Datta P, Li G, Yang B, Zhao X, Baik JY, Gemmill TR, et al. Bioengineered Chinese hamster ovary cells with golgi-targeted 3-O-sulfotransferase-1 biosynthesize heparan sulfate with an antithrombin-binding site. J Biol Chem. 2013;288(52):37308-18. https://doi.org/10.1074/jbc.M113.519033.

52. Stringer SE, Gallagher JT. Specific binding of the chemokine platelet factor 4 to heparan sulfate. J Biol Chem. 1997;272(33):20508-14. https://doi.org/10.1 074/jbc.272.33.20508.

53. Kashoki M, Hanaizi Z, Yordanova S, Veselý R, Bouygues C, Llinares J, et al. A comparison of EMA and FDA decisions for new drug marketing applications 2014-2016: concordance, discordance, and why. Clin Pharmacol Ther. 2020; 107(1):195-202. https://doi.org/10.1002/cpt.1565.

54. Curtis B. Drug-induced immune thrombocytopenia: incidence, clinical features, laboratory testing, and pathogenic mechanisms. Immunohematology. 2014;30(2):55-65. https://pubmed.ncbi.nlm.nih.gov/2 5247620/. https://doi.org/10.21307/immunohematology-2019-099.

55. Krauel K, Pötschke C, Weber C, Kessler W, Fürll B, Ittermann T, et al. Platelet factor 4 binds to bacteria, inducing antibodies cross-reacting with the major antigen in heparin-induced thrombocytopenia. Blood. 2011;117(4):1370-8. https://doi.org/10.1182/blood-2010-08-301424.

56. Krauel K, Weber C, Brandt S, Zähringer U, Mamat U, Greinacher A, et al. Platelet factor 4 binding to lipid a of gram-negative bacteria exposes PF4/ heparin-like epitopes. Blood. 2012;120(16):3345-52. https://doi.org/10.1182/ blood-2012-06-434985.

57. Tsilingiris D, Vallianou NG, Karampela I, Dalamaga M. Vaccine induced thrombotic thrombocytopenia: the shady chapter of a success story. Metab Open. 2021;11:100101. https://doi.org/10.1016/j.metop.2021.100101.

58. Geeraerts T, Montastruc F, Bonneville F, Mémier V, Raposo N, Darcourt J, et al. Oxford-AstraZeneca COVID-19 vaccine-induced cerebral venous thrombosis and thrombocytopaenia: a missed opportunity for a rapid return of experience. Anaesth Crit Care Pain Med. 2021;40(4):100889. https://doi. org/10.1016/j.accpm.2021.100889.

59. Ferro JM, de Sousa DA, Coutinho JM, Martinelli I. European stroke organization interim expert opinion on cerebral venous thrombosis occurring after SARS-CoV-2 vaccination. Eur Stroke J. 2021: 23969873211030840 https://doi.org/10.1177/23969873211030842.

60. Gessler F, Schmitz AK, Dubinski D, Bernstock JD, Lehmann F, Won S-Y, et al. Neurosurgical considerations regarding decompressive craniectomy for intracerebral hemorrhage after SARS-CoV-2-vaccination in vaccine induced thrombotic thrombocytopenia-VITT. J Clin Med. 2021; https://pubmed. ncbi.nlm.nih.gov/34202817/.

61. McGonagle D, De Marco G, Bridgewood C. Mechanisms of immunothrombosis in vaccine-induced thrombotic thrombocytopenia (VITT) compared to natural SARS-CoV-2 infection. J Autoimmun. 2021;121: 102662. https://pubmed.ncbi.nlm.nih.gov/34051613/. https://doi.org/10.101 6/j.jaut.2021.102662.

62. Vayne C, Rollin J, Gruel Y, Pouplard C, Galinat H, Huet O, et al. PF4 immunoassays in vaccine-induced thrombotic thrombocytopenia. N Engl J Med. 2021;385(4):376-8. https://www.nejm.org/doi/full/10.1056/NEJMc2106383.

63. Schultz NH, Sørvoll IH, Michelsen AE, Munthe LA, Lund-Johansen F, Ahlen MT, et al. Thrombosis and thrombocytopenia after ChAdOx1 nCoV-19 vaccination. N Engl J Med. 2021;384(22):2124-30. https://doi.org/10.1056/ NEJMoa2104882.

64. McDonald I, Murray SM, Reynolds CJ, Altmann DM, Boyton RJ. Comparative systematic review and meta-analysis of reactogenicity, immunogenicity and efficacy of vaccines against SARS-CoV-2. NPJ Vaccines. 2021;6(1):74. https:// doi.org/10.1038/s41541-021-00336-1.

65. Mayo KH, llyina E, Roongta V, Dundas M, Joseph J, Lai CK, et al. Heparin binding to platelet factor-4 an NMR and site-directed mutagenesis study: 
arginine residues are crucial for binding. Biochem J. 1995;312(2):357-65. https://doi.org/10.1042/bj3120357.

66. Greinacher A, Alban S, Omer-Adam MA, Weitschies W, Warkentin TE. Heparin-induced thrombocytopenia: a stoichiometry-based model to explain the differing immunogenicities of unfractionated heparin, lowmolecular-weight heparin, and fondaparinux in different clinical settings. Thromb Res. 2008;122(2):211-20. https://doi.org/10.1016/j.thromres.2007.11. 007.

67. D'Angelo A, Della Valle P, Fattorini A, Crippa L. Disappearance of anti-PF4/ heparin antibodies under prolonged fondaparinux administration in a patient with DVT associated with LMWH-induced thrombocytopenia. Thromb Haemost. 2006;95(3):573-5. https://pubmed.ncbi.nlm.nih.gov/1652 5590/. https://doi.org/10.1160/TH05-11-0722.

68. Greinacher A, Juhl D, Strobel U, Wessel A, Lubenow N, Selleng K, et al. Heparin-induced thrombocytopenia: a prospective study on the incidence, platelet-activating capacity and clinical significance of antiplatelet factor 4/ heparin antibodies of the lgG, IgM, and IgA classes. J Thromb Haemost. 2007;5(8):1666-73. https://doi.org/10.1111/j.1538-7836.2007.02617.x.

69. Alsaleh KA, Al-Nasser SMA, Bates SM, Patel A, Warkentin TE, Arnold DM. Delayed-onset HIT caused by low-molecular-weight heparin manifesting during fondaparinux prophylaxis. Am J Hematol. 2008;83(11):876-8. https:// pubmed.ncbi.nlm.nih.gov/18803278/. https://doi.org/10.1002/ajh.21273.

70. Warkentin TE, Pai M, Sheppard JI, Schulma S, Spyropoulos AC, Eikelboom JW. Fondaparinux treatment of acute heparin-induced thrombocytopenia confirmed by the serotonin-release assay: a 30-month, 16-patient case series. J Thromb Haemost. 2011;9(12):2389-96. http://doi.wiley.com/10.1111/ j.1538-7836.2011.04487.x.

71. Peshattiwar $\mathbf{V}$. The fondaparinux paradox: fondaparinux-related heparininduced thrombocytopenia. Indian J Crit Care Med. 2018;22(2):116-8. https://www.jiccm.org/doi/10.4103/ijccm.IJCCM_189_17.

72. Manji F, Warkentin TE, Sheppard JAI, Lee A. Fondaparinux cross-reactivity in heparin-induced thrombocytopenia successfully treated with high-dose intravenous immunoglobulin and rivaroxaban. Platelets. 2020;31(1):124-7. https://pubmed.ncbi.nlm.nih.gov/31397594/. https://doi.org/10.1080/095371 04.2019 .1652263$.

73. Dulicek P, Ivanova E, Kostal M, Fiedlerova Z, Sadilek P, Hirmerova J. Heparininduced thrombocytopenia treated with fondaparinux: single center experience. Int Angiol. 2020;39(1):76-81. https://pubmed.ncbi.nlm.nih.gov/31 782283/. https://doi.org/10.23736/S0392-9590.19.04247-0.

74. Krečak I, Tomac G, Škugor J, Gverić-Krečak V, Pulanić D. In vivo and in vitro cross-reactivity to fondaparinux in a stroke patient with lgG-PF4/heparin antibody-negative delayed-onset heparin-induced thrombocytopenia. Blood Transfus. 2020;18(4):322-5. https://pubmed.ncbi.nlm.nih.gov/32530398. https://doi.org/10.2450/2020.0037-20.

75. Nguyen TH, Medvedev N, Delcea M, Greinacher A. Anti-platelet factor 4/ polyanion antibodies mediate a new mechanism of autoimmunity. Nat Commun. 2017:8(1):14945. https://doi.org/10.1038/ncomms14945.

76. Juhl D, Eichler P, Lubenow N, Strobel U, Wessel A, Greinacher A. Incidence and clinical significance of anti-PF4/heparin antibodies of the $\operatorname{lgG}$, IgM, and IgA class in 755 consecutive patient samples referred for diagnostic testing for heparin-induced thrombocytopenia. Eur J Haematol. 2006;76(5):420-6. https://doi.org/10.1111/j.1600-0609.2005.00621.x.

77. Amiral J, Wolf M, Fischer AM, Boyer-Neumann C, Vissac AM, Meyer D. Pathogenicity of IgA and/or IgM antibodies to heparin-PF4 complexes in patients with heparin-induced thrombocytopenia. Br J Haematol. 1996;92(4): 954-9. https://doi.org/10.1046/j.1365-2141.1996.407945.x.

78. Denomme GA, Warkentin TE, Horsewood P, Sheppard JA, Warner MN, Kelton JG. Activation of platelets by sera containing IgG1 heparindependent antibodies: an explanation for the predominance of the fc gammaRIla "low responder" (his131) gene in patients with heparin-induced thrombocytopenia. J Lab Clin Med. 1997;130(3):278-84. http://www.ncbi. nlm.nih.gov/pubmed/9341987. https://doi.org/10.1016/S0022-2143 (97)90022-6.

79. Nevzorova TA, Mordakhanova ER, Daminova AG, Ponomareva AA, Andrianova IA, Le Minh G, et al. Platelet factor 4-containing immune complexes induce platelet activation followed by calpain-dependent platelet death. Cell Death Dis. 2019;5(1):106. https://doi.org/10.1038/s41420019-0188-0.

80. Litvinov RI, Yarovoi SV, Rauova L, Barsegov V, Sachais BS, Rux AH, et al. Distinct specificity and single-molecule kinetics characterize the interaction of pathogenic and non-pathogenic antibodies against platelet factor 4- heparin complexes with platelet factor. J Biol Chem. 2013;288(46):33060-70. https://doi.org/10.1074/jbc.M113.481598.

81. Ziporen L, Li ZQ, Park KS, Sabnekar P, Liu WY, Arepally G, et al. Defining an antigenic epitope on platelet factor 4 associated with heparin-induced thrombocytopenia. Blood. 1998;92(9):3250-9. https://doi.org/10.1182/blood. v92.9.3250.

82. Cai Z, Yarovoi SV, Zhu Z, Rauova L, Hayes V, Lebedeva T, et al. Atomic description of the immune complex involved in heparin-induced thrombocytopenia. Nat Commun. 2015;6(1):8277. https://doi.org/10.1038/ ncomms9277.

83. Arepally GM, Kamei S, Park KS, Kamei K, Li ZQ, Liu W, et al. Characterization of a murine monoclonal antibody that mimics heparin-induced thrombocytopenia antibodies. Blood. 2000;95(5):1533-40. https://doi.org/1 0.1182/blood.V95.5.1533.005k01_1533_1540.

84. Vayne C, Guéry E-A, Rollin J, Baglo T, Petermann R, Gruel Y. Pathophysiology and diagnosis of drug-induced immune thrombocytopenia. J Clin Med. 2020;9(7):2212. https://pubmed.ncbi.nlm.nih.gov/32668640/. https://doi.org/1 $0.3390 / \mathrm{jcm} 9072212$.

85. Parren PWHI, Warmerdam PAM, Boeije LCM, Arts J, Westerdaal NAC, Vlug A, et al. On the interaction of IgG subclasses with the low affinity FcyRlla (CD32) on human monocytes, neutrophils, and platelets. Analysis of a functional polymorphism to human IgG2. J Clin Invest. 1992;90(4):1537-46. https://doi.org/10.1172/JCl116022.

86. Pouplard C, lochmann S, Renard B, Herault O, Colombat P, Amiral J, et al. Induction of monocyte tissue factor expression by antibodies to heparinplatelet factor 4 complexes developed in heparin-induced thrombocytopenia. Blood. 2001;97(10):3300-2. https://pubmed.ncbi.nlm.nih. gov/11342462/. https://doi.org/10.1182/blood.V97.10.3300.

87. Cines DB, Tomaski A, Tannenbaum S. Immune endothelial-cell injury in heparin-associated thrombocytopenia. N Engl J Med. 1987;316(10):581-9. https://doi.org/10.1056/NEJM198703053161004.

88. Padmanabhan A, Jones CG, Curtis BR, Bougie DW, Sullivan MJ, Peswani N, et al. A novel PF4-dependent platelet activation assay identifies patients likely to have heparin-induced thrombocytopenia/thrombosis. Chest. 2016; 150(3):506-15. https://doi.org/10.1016/j.chest.2016.02.641.

89. Warkentin TE. Laboratory diagnosis of heparin-induced thrombocytopenia. Int J Lab Hematol. 2019;41(Suppl 1):15-25. https://doi.org/10.1111/ijlh.12993.

90. Nagler M, Bachmann LM, Ten Cate H, Ten Cate-Hoek A. Diagnostic value of immunoassays for heparin-induced thrombocytopenia: a systematic review and meta-analysis. Blood. 2016;127(5):546-57. https://doi.org/10.1182/ blood-2015-07-661215.

91. Železnik K, Rožman P, Kocjan E, Maličev E. Heparin-induced thrombocytopenia: ELISA optical density value and 4T score in correlation with panel donor platelets activation in functional flow cytometric assay. Blood Transfus. 2021;19(1):77-84. https://pubmed.ncbi.nlm.nih.gov/33 085589/. https://doi.org/10.2450/2020.0120-20.

92. Brodard J, Alberio L, Angelillo-Scherrer A, Nagler M. Accuracy of heparininduced platelet aggregation test for the diagnosis of heparin-induced thrombocytopenia. Thromb Res. 2020;185:27-30. https://pubmed.ncbi.nlm. nih.gov/31739198/. https://doi.org/10.1016/j.thromres.2019.11.004.

93. Tardy B, Lecompte T, Mullier F, Vayne C, Pouplard C. Detection of plateletactivating antibodies associated with heparin-induced thrombocytopenia. J Clin Med. 2020;9(4):1226. https://pubmed.ncbi.nlm.nih.gov/32344682/. https://doi.org/10.3390/jcm9041226.

94. Marchetti M, Barelli S, Zermatten MG, Monnin-Respen F, Matthey-Guirao E, Nicolas N, et al. Rapid and accurate Bayesian diagnosis of heparin-induced thrombocytopenia. Blood. 2020;135(14):1171-84. https://pubmed.ncbi.nlm. nih.gov/31945147/. https://doi.org/10.1182/blood.2019002845.

95. Gruel Y, De Maistre E, Pouplard C, Mullier F, Susen S, Roullet S, et al. Diagnosis and management of heparin-induced thrombocytopenia. Anaesth Crit Care Pain Med. 2020;39(11):291-310. https://doi.org/10.5694/mja2.50213.

96. Pouplard C, Gueret P, Fouassier M, Ternisien C, Trossaert M, Régina S, et al. Prospective evaluation of the "4Ts" score and particle gel immunoassay specific to heparin/PF4 for the diagnosis of heparin-induced thrombocytopenia. J Thromb Haemost. 2007;5(7):1373-9. https://doi.org/1 0.1111/j.1538-7836.2007.02524.x.

97. Tardy-Poncet B, de Maistre E, Pouplard C, Presles E, Alhenc-Gelas M, Lasne $D$, et al. Heparin-induced thrombocytopenia: construction of a pretest diagnostic score derived from the analysis of a prospective multinational database, with internal validation. J Thromb Haemost https://doi.org/1 0.1111/jth.15344. 2021. 
98. Warkentin TE. Challenges in detecting clinically relevant heparin-induced thrombocytopenia antibodies. Hamostaseologie. 2020;40(04):472-84. https:// doi.org/10.1055/a-1223-3329.

99. Greinacher A, Thiele T, Warkentin TE, Weisser K, Kyrle PA, Eichinger S. Thrombotic thrombocytopenia after ChAdOx1 nCov-19 vaccination. N Engl J Med. 2021;384(22):2092-101. https://doi.org/10.1056/NEJMoa2104840.

100. Marchetti M, Zermatten MG, Bertaggia Calderara D, Aliotta A, Alberio L. Heparin-induced thrombocytopenia: a review of new concepts in pathogenesis, diagnosis, and management. J Clin Med. 2021;10(4):683. https://pubmed.ncbi.nlm.nih.gov/33578859/. https://doi.org/10.3390/jcm1 0040683.

101. Sheridan D, Carter C, Kelton JG. A diagnostic test for heparin-induced thrombocytopenia. Blood. 1986;67(1):27-30. https://doi.org/10.1182/blood. v67.1.27.27.

102. Minet $\mathrm{V}$, Dogné JM, Mullier F. Functional assays in the diagnosis of heparininduced thrombocytopenia: a review. Molecules. 2017;22(4):617. https://doi. org/10.3390/molecules22040617.

103. Warkentin TE, Nazy I, Sheppard JAl, Smith JW, Kelton JG, Arnold DM. Serotonin-release assay-negative heparin-induced thrombocytopenia. Am J Hematol. 2020;95(1):38-47. https://pubmed.ncbi.nlm.nih.gov/31621093/. https://doi.org/10.1002/ajh.25660.

104. Morel-Kopp M-C, Mullier F, Gkalea V, Bakchoul T, Minet V, Elalamy I, et al. Heparin-induced multi-electrode aggregometry method for heparininduced thrombocytopenia testing: communication from the SSC of the ISTH. J Thromb Haemost. 2016;14(12):2548-52. https://doi.org/10.1111/jth.13 516.

\section{Publisher's Note}

Springer Nature remains neutral with regard to jurisdictional claims in published maps and institutional affiliations.

Ready to submit your research? Choose BMC and benefit from:

- fast, convenient online submission

- thorough peer review by experienced researchers in your field

- rapid publication on acceptance

- support for research data, including large and complex data types

- gold Open Access which fosters wider collaboration and increased citations

- maximum visibility for your research: over $100 \mathrm{M}$ website views per year

At $\mathrm{BMC}$, research is always in progress.

Learn more biomedcentral.com/submissions 